\title{
A Análise do Videoclipe Sob a Perspectiva da Análise do Discurso Francesa para o Ensino da Língua Inglesa
}

\author{
Videoclipe Analysis under the Perspective of the French Speech Analysis for English \\ Language Education
}

\author{
Rosangela Zimmer*a; Lucy Ferreira Azevedo ${ }^{\mathrm{a}}$ \\ aUniversidade de Cuiabá, Programa de Pós-Graduação Stricto Sensu em Ensino. MT, Brasil. \\ *E-mail: zimmer.ro@globo.com
}

\begin{abstract}
Resumo
As vivências como professora na área da língua inglesa da Educação Básica me motivaram a estudar leitura. A inquietação que surgiu foi: contextualizar culturalmente os temas propostos levaria o aluno a pensar a língua estrangeira com criticidade e consciência das diferenças entre esta e sua língua nativa? Nesta perspectiva, o objetivo deste artigo é documentar uma oficina de leitura em que houve a relação história e arte com critérios definidores do modo de funcionamento da Análise do Discurso francesa e a sua orientação em direção a problemas práticos do cotidiano, relacionados à língua e à comunicação. Para tanto, o estudo analisou e desenvolveu a leitura de um clipe em língua inglesa do ponto de vista da vida contemporânea, repensando o seu objeto de estudo, a escola, os alunos e os professores em diferentes contextos: corpo, etnia, nacionalidade, gênero, classe social, entre outros tópicos, conforme os textos estudados. O método de abordagem foi qualitativo, em pesquisa descritiva e bibliográfica com base nos autores da área da Análise do Discurso francesa, em apenas um clipe, entre oito oficinas compostas de clipes com temas diversificados em linguagem conotativa. Espera-se que o estudo aqui proposto culmine em um ensino que leve o estudante a pensar a outra cultura e, com ela, outras habilidades e competências em língua inglesa e consequentemente evolua com maior fluidez.
\end{abstract}

Palavras-chave: Ensino. Língua Inglesa. Videoclipe.

\begin{abstract}
The experiences as a teacher in the English language area of Basic Education motivated me to study reading. The concern that arose was to culturally contextualizing the proposed themes lead the student to think the foreign language with criticism and awareness of the differences between it and his native language? In this perspective, the aim of this article is to document a reading workshop in which there was a relationship between history and art with defining criteria of the way French Discourse Analysis works and its orientation towards practical everyday problems related to language and communication. To this end, the study analyzed and developed the reading of an English-language clip from the point of view of contemporary life, rethinking its object of study, school, students and teachers in different contexts: body, ethnicity, nationality, gender, social class, among other topics, according to the texts studied. The method of approach was qualitative, in descriptive and bibliographical research based on the authors of the French Discourse Analysis area, in only one clip, among eight workshops with clips with diverse themes in connotative language. It is expected that the study proposed here will culminate in a teaching that leads the student to think about another culture and, with it, other skills and competences in English language and consequently evolve with greater fluidity.
\end{abstract}

Keywords: Teaching. English Language. Video Clip.

\section{Introdução}

A linguagem como prática social vem sendo alvo de muita teorização por parte de várias áreas das Ciências Humanas. E, apesar de trabalhar linguagem, os professores de língua estrangeira em geral ainda trabalham textos com base na memorização e prática de exercícios estruturais. No entanto, há um grande campo a ser explorado, como o uso de Tecnologias Digitais da Informação e Comunicação TDIC, aqui escolhido o videoclipe para um breve ensaio, e a conexão entre vida/história e texto literário, ou seja, como o leitor recebe a obra literária e de que forma estabelece a relação entre ela e sua própria vida. Surge desta comunhão conceitual, então, a hipótese de que o ensino de inglês ou de qualquer outra língua estrangeira poderia ser potencializado pela imersão cultural, momento em que o estudante insere em sua própria história/vida as experiências propostas pela sua leitura.

Objetivando associar história e arte, com a experimentação do videoclipe como corpus, pretende-se ampliar o ensino de língua inglesa com a adoção da Análise do Discurso francesa como direcionadora do estudo do texto conotativo proposto pelo clipe musical.

A ampliação do acervo cultural do aluno, segundo suas leituras de mundo, com uma reflexão qualitativa, descritiva e bibliográfica foi desenvolvida para repensar a escola, os alunos e professores em diferentes contextos: corpo, etnia, nacionalidade, gênero, classe social, entre outros tópicos. Para tanto, a orientação teórica da Análise do Discurso francesa (doravante $\mathrm{AD}$ ) será o suporte para entendimento do corpus escolhido, um videoclipe.

Espera-se que o estudo aqui proposto culmine em um ensino que leve o estudante a pensar a outra cultura e, consequentemente, o professor consiga refletir sobre o ensino 
de língua além do estruturalismo que, segundo o enfoque deste trabalho, é necessário, mas limitante da evolução do aluno.

\section{Material e Métodos}

A metodologia aplicada para a pesquisa foi a qualitativa e interpretativa, a partir das discussões do Grupo de Pesquisa da Linha 1 (Linguagem e seus Códigos) sobre Tecnologias da Informação e Comunicação - TIC ligadas à Educação.

Foi escolhido um videoclipe para um breve ensaio, estabelecendo a conexão entre vida/história e texto literário. Objetivando associar história e arte, com a experimentação do videoclipe como corpus, oficinas foram desenvolvidas com a adoção da Análise do Discurso francesa como direcionadora do estudo do texto conotativo proposto pelo clipe musical, além de outros autores basilares: Hall (2006), Santos (2018), Tardif (2014), Pêcheux (1990), entre outros.

Foram estudados oito clipes com alunos do $9^{\circ}$ ano em uma escola pública de Cuiabá-MT e, na limitação deste artigo, farse-á a exemplificação de apenas uma oficina.

\section{Resultados e Discussão}

\subsection{A Análise do Discurso francesa e o ensino da língua inglesa a partir da leitura do videoclipe}

À primeira vista, é fundamental ter compreensão de que os novos modelos de ensino de uma língua adicional envolvem modelos híbridos, no sentido de serem compostos por áreas diferentes: Linguagem, Linguística, TDIC, Semiótica e Sociologia.

Há atualmente um novo perfil de aprendizagem que desagrega tradicionais práticas de ensino e altera as perspectivas de aprendizagens até então bem solidificadas no universo educacional. Consequentemente novas perspectivas suscitam readequações essenciais ao conceito do que foi, do que é e do que será ser professor nos moldes da sociedade atual vai ao encontro do conceito de identidade cultural. As identidades que compunham as paisagens sociais e que asseguravam a conformidade subjetiva com as necessidades objetivas da cultura, estão em colapso, devido as mudanças estruturais e institucionais. O processo de identificação, por meio do projetamos nossas identidades culturais tornou-se provisório, variável e problemático (BRONCKART, 2005; HALL, 2006; SANTOS, 2018)

A manutenção da função docente, sob pressão de novas necessidades, profissão que era tão fundamental na vida dos estudantes encontra-se socialmente desvalorizada. Nessa perspectiva, Tardif (2014) demonstra que na função docente, a lógica da transmissão dos saberes experienciais, curriculares e pedagógicos tende a ser justificada pela legitimação social como espaço de verdade. Sendo que a relação que os professores estabelecem com a cultura impacta substancialmente na maneira como os estudantes interagem culturalmente.

Talvez por isso, no bojo das recentes pesquisas em ensino estejam em evidência as linguagens trazidas pelos alunos para a escola a fim de serem convertidas em práticas de ensino, com o propósito de que tanto aprendizes quanto ensinantes compreendam o universo das necessidades de aprendizagem com as quais se deparam.

Pensando no que foi exposto anteriormente, o novo paradigma de ensino vem sendo implementado tendo como norteador a Base Nacional Comum Curricular (BNCC, 2017), que visa desenvolver competências e habilidades a partir de uma visão interdisciplinar/transdisciplinar. Portanto, percebese que, atrelado ao ensino da língua, há a preocupação com as áreas das Ciências Humanas e Sociais.

O ensino de uma língua estrangeira - LE permite o acesso ao mundo globalizado e dá condições ao exercício da cidadania, pois permite a interação entre diversos contextos. Ademais, a ênfase está no caráter formativo e numa perspectiva de educação linguística consciente e crítica, como também objetiva um aluno multiletrado dentro de uma perspectiva de multimodalidade de textos, com a finalidade de favorecer a criatividade e autonomia dos alunos frente aos conteúdos que lhes são expostos, nesta proposta, sob o olhar da abordagem interacionista sociodiscursiva de Bronckart (2005). E esta multimodalidade, como convergência de mais de uma linguagem na comunicação, trata-se da combinação de um fenômeno já percebido em vários estudos em áreas de comunicação visual, artes/design e linguística.

Lê-se o videoclipe musical como um recurso multimodal no ensino da língua inglesa que permite redirecionar o olhar aos invisíveis da sociedade, segundo a BNCC (2017). Para Giddens (2002), esse evento que envolve o videoclipe, descreve-se como alta modernidade e resulta da influência dos acontecimentos distantes sobre a intimidade do eu, o que por sua vez se torna cada vez mais natural com o desenvolvimento da comunicação de massa.

Esta ferramenta possibilita leituras alicerçadas no visual, linguístico, sonoro, imagético, tipográfico e cultural. Em consonância a essa atividade multimodal, o videoclipe permite aprimorar o listening and speaking, com efeito validando o eixo da oralidade. A combinação dos elementos encontrados nos clipes musicais assegura a leitura semiótica e a interpretação que auxiliam e estimulam as atividades orais. Nesse sentido:

A pedagogia dos multiletramentos abarca práticas que fazem parte das culturas vivenciadas pelos alunos linguagens e gêneros que são comuns no seu cotidiano. Busca interpretar os contextos sociais e culturais tendo em vista uma prática transformadora. O objetivo é aprender a relacionar com o mundo e a refletir sobre ele de uma maneira diferente do habitual, que já não traz muitos significados. Os letramentos multissemióticos propõem a leitura e a produção textual em diversas linguagens e semioses [...]. Portanto, se faz necessário trabalharmos não apenas com textos impressos, mas também com as mídias analógicas e digitais. (ORMOND, 2016, p.35).

A mídia constantemente apresenta notícias que falam sobre imigrantes, algumas demonstram que o ser humano 
pode ser solidário, no entanto, outras mostram violência, preconceito e xenofobia.

Sabe-se também que os fluxos migratórios ao redor do globo terrestre são constantes, alguns saem do seu país de origem por motivo de catástrofes naturais, outros por guerras, exclusão social, miséria e fome. Dentre eles, o sofrimento do imigrante haitiano não pode ser menosprezado, um ser humano que ficou despatriado devido à miséria gerada por conta do terremoto no país, mas, acima de tudo, que veio para o Brasil com uma grande expectativa, um sonho de futuro melhor, no entanto, sem prever este território inóspito.

Para fazer a leitura deste contexto, recorre-se à orientação teórica da Análise do Discurso francesa, quando direciona o leitor a perceber a determinação histórica dos processos semânticos.

Através das estruturas que lhe são próprias, toda língua está necessariamente na relação com o 'não está', o 'não está mais', o 'ainda não está' e o 'nunca estará' da percepção imediata; nela se inscreve assim a eficácia omni-histórica da ideologia como tendência incontornável a representar as origens e os fins últimos, o alhures, o além e o invisível (PÊCHEUX, 1990, p. 8)

Assim, insere-se a orientação teórica também da linguística como teoria dos mecanismos sintáticos e dos processos de enunciação.

A linguagem, aqui entendida como muito mais que apenas um sistema de regras formais com os estudos discursivos. O artigo apropria-se da sua prática no videoclipe, descortinando o simbólico, com a divisão política dos sentidos em sua fragilidade. Portanto, um estudo para além da frase. Observa o discurso em seu amálgama sujeito e sua formação discursiva, bem como sua história, ideologia e também a formação do leitor.

Portanto, é nas circunstâncias nas quais esses imigrantes parecem pisar e terreno instável é que se busca analisar que sentidos serão construídos em uma aula de inglês, a partir da projeção do videoclipe helping Haiti - Everybody hurts (2010), gravado por um grupo de artistas.

O clipe musical aborda o terremoto e a reconstrução do Haiti após a catástrofe. A nova versão foi produzida pelos artistas: Alexandra Burke, Cheryl Cole, JLS, James Blunt, James Morrison, Joe McElderry, Jon Bon Jovi, Kylie Minogue, Leona Lewis, Mariah Carey, Michael Bublé, Mika, Miley Cyrus, Robbie Williams, Rod Stewart, Susan Boyle, Take That e Westlife Group.

A versão do videoclipe emociona, mas, acima de tudo, teve a intenção nobre de arrecadar dinheiro para as vítimas do sismo no Haiti em 2010. A letra original foi escrita na década de 80 pelo baterista da banda R.E.M. e tornou-se um dos maiores sucessos da banda.

A partir do uso do recurso videoclipe, pode-se desenvolver competências e habilidades da língua inglesa nos alunos, como também sensibilizar sobre o sofrimento alheio, principalmente os excluídos socialmente, pois a perspectiva que a proposta abraça é entender a cultura como uma "chave para o universo" (GEERTZ, 1978, p.13), a fim de ampliar horizontes e unir os povos.

Sob uma perspectiva inclusiva é que a utilização do videoclipe "Everybody Hurts" se fundamenta em sala de aula, pois possibilita um foco na abordagem comunicativa, leva em consideração o aspecto social da linguagem e permite que o aluno possa se comunicar de modo significativo com o seu interlocutor por meio da língua inglesa.

\subsection{Everybody Hurts - a canção}

A partir do videoclipe representado pela linguagem verbal e não verbal, em que se espera que o leitor produza significados em compreensão e em comunhão com o mundo, consequentemente ampliar a condição humana, ou seja, tornar-se mais humanizado perante o sofrimento do próximo, pretende-se ler sob o ângulo da $\mathrm{AD}$ que conduz o trabalho para a leitura dos marginalizados/invisíveis da sociedade. $\mathrm{O}$ aluno insere-se na teia de sentidos criada pelos seres humanos que desenvolve fundamentalmente a percepção de um conjunto de condutas e valores éticos a serem seguidos - assim como entende Geertz (1973).

De acordo com Moita Lopes (2006), “a escolha em relação a que valores devem ser preferidos tem que ser baseada na exclusão daqueles que causam sofrimento humano ou façam mal aos outros". Nesta perspectiva, na leitura da letra, tem-se os sentidos mobilizados na letra de "Everybody Hurts" por artistas que querem ajudar na causa humanitária.

O Mundo da época da educação tradicional de certa maneira comportava o estudo apenas da estrutura da língua, no entanto, no atual contexto do século XXI, os estudantes aprendem interagindo por meio da criatividade. De certo que, a integração das tecnologias digitais no espaço escolar, em especial no caso do Inglês como língua estrangeira (BRAGA, 2012), abre as portas para o mundo fora da sala de aula e oferece insumo e imersão natural da língua, criando oportunidades individuais e coletivas de desenvolvimento das habilidades de leitura, escrita, fala e compreensão oral.

Percebe-se o engajamento político na letra da música dos autores/produtores do clipe ou uma formação discursiva - aqui analisada como projeção da ideologia no dizer Orlandi (2012) que deixou claro o intento de discutir a questão, embora em discurso lúdico.

O Discurso, na canção, produzido em diferentes linguagens que se somam para delatar o sofrimento do povo haitiano, porque na letra da música "Everybody Hurts", em português "Todo Mundo Sofre", o título faz refletir e convida à solidariedade nas questões sociais. A produção artística na versão "helping Haiti" é envolvente, tensa conforme a proposta da música.

Para cumprir o seu propósito, o videoclipe utilizou algumas imagens reais do terremoto no Haiti. De acordo com Koch (2006), assim como o texto, os videoclipes são concebidos por uma mescla de enunciados para concatenar sentidos, a fim de 
que o ouvinte consiga interpretar e identificar o proferido ou não. Portanto, ao ler-se uma letra de música no clipe musical, ampliam-se as perspectivas de reinventar o mundo.

$\mathrm{O}$ videoclipe em análise é um pequeno filme, um curtametragem atrelado ao som de uma única música com imagens chocantes e reais sobre a tragédia do Haiti. No texto não

No fragmento da música "Everybody Hurts":

Don't let yourself go

'Cause everybody cries

And everybody hurts, sometimes

Sometimes everything is wrong

Now it's time to sing along

When your day is night alone (hold on, hold on)

If you feel like letting go (hold on)

If you think you've had too much of this life

To hang on

'Cause everybody hurts

Take comfort in your friends

Everybody hurts, oh, no

Don't throw your hand

If you feel like you're alone

No, no, no, you're not alone verbal, uma população negra e sofrida, constituída de velhos, adultos e crianças.

A análise do discurso desenvolvida, para a vivência em sala de aula, contará com a história de leituras de cada aluno, assim como estará vinculada às palavras e ao imaginário do leitor, a sua história.

Não se deixe levar

Porque todos choram

E todo mundo sofre às vezes

Às vezes algo está errado

Agora é hora de cantarmos juntos

Quando seu dia é uma noite solitária (aguente firme, aguente firme)

Se você se sentir que está partindo (aguente firme)

Se você pensa que já teve demais dessa vida, bem... calma

Porque todo mundo sofre... às vezes

Tenha conforto em seus amigos

Todo mundo sofre

Não solte sua mão. Oh, não

Não solte sua mão

Quando você se sentir como se estivesse sozinho, não, não, você não está sozinho
Aos olhos e ouvidos do leitor/ouvinte, o clipe musical é triste, porém conduz o leitor/ouvinte à reflexão, porque mexe com as emoções. No videoclipe da música "Everybody Hurts", na versão helping Haiti, o objetivo é incentivar o lado humanitário e solidário da humanidade. Na palavra "hold on" (aguente firme) percebe-se uma forma de inspirar a viver, superar a tristeza, buscar motivos para ser feliz. Percebe-se que a formação ideológica dos autores é humanista, com a percepção do coletivo e humanitário como fórmula para um mundo melhor.

Esta canção também já esteve vinculada a outras campanhas publicitárias de conscientização e solidariedade: Campanha não Beba e Dirija: Transport Accident Commision (TAC), de Victória na Austrália, campanha Hold On dos Médicos Sem Fronteiras e campanha solidária Helping Haiti.

No primeiro verso, "Não se deixe levar", o leitor pode ser levado a pensar que pode ser um alerta contra o já-dito, ideologicamente conduzido às populações para que não aceitem o que a natureza, ou a vida lhes impõe, o que fica registrado no verso, mas é um verso polissêmico. É realmente um apelo individual à aceitação, para que a pessoa aguente seu sofrimento e não há outro verso que sinalize para a esperança de mudança, a não ser o apoio solidário. Sob a orientação da $\mathrm{AD}$, no entanto, o valor da expressão pode ser um incentivo à reação, como uma construção em antítese: não se deixe levar pelo desânimo/reaja contra uma situação repetitiva e que comumente os pobres e negros sofrem.

Conforme Orlandi (2007), a língua funciona ideologicamente e o sentido tem uma materialidade linguística e histórica. A letra da canção do clipe, ao abordar a catástrofe, omite a repetição em que as populações historicamente vêm sofrendo e não há ajuda humanitária e projeção de um futuro melhor diante do caos. Pouco é feito para controlar o que pobres e negros aceitam como uma situação "predestinada": "Porque todo mundo sofre... às vezes" / "Tenha conforto em seus amigos" são exemplos.

É comprometedora a expressão “às vezes”, porque parece que as instituições não se importam com a repetidas catástrofes que a humanidade vem sofrendo, no contexto da pobreza absoluta na Índia, zonas de guerra, "círculo de fogo" com vulcões e tsunamis e todas as outras situações.

Nos versos "Take comfort in your friends" e "you're not alone", há a representação de apoio na segurança que o próximo pode assegurar com a ideia de que a dor será amenizada. E o verso "Don't throw your hand" demonstra que, segurando na mão do próximo, o sofredor está confiando na ajuda que lhe é dada.

O verso "Agora é hora de cantarmos juntos" traz a música como um estandarte, meio de luta.

A leitura/interpretação do videoclipe é realizada a partir da representação das imagens as quais demonstram os haitianos feridos, alguns sendo medicados, o cenário catastrófico devido à destruição do terremoto, fundamentando o título da canção "Everybody Hurts", ou seja, todo mundo sofre. Portanto, o sofrimento exige consciência de si, envolve as emoções, tem efeito nas relações pessoais da pessoa e um impacto no corpo e na alma. No entanto, o poder constituído parece ser uma ilha à parte, porque nada faz para estrategicamente não permitir a repetição.

O contexto haitiano é de catástrofe coletiva e no extremo da vivência humana, porém o aluno pode fazer inferências com a sua própria vida, porque alguns dramas vividos no Haiti fazem parte do cotidiano de alguns estudantes ou, certamente, de seu imaginário e a fome, falta de alimentos, o desconforto 
físico-material e emocional podem ser motivações fortíssimas para uma comunhão entre haitianos e brasileiros na ajuda para que os refugiados possam ser apoiados aqui.

\section{Conclusão}

Atualmente, os clipes estão associados ao lançamento das músicas pela indústria cultural. Junto a eles, outros valores são divulgados, extrapolando a apreciação sonora: moda, costumes, ditames para diferentes expressões no cabelo, expressão verbal e gestual, entre outras interações.

Assim, o objetivo de associar história e arte com critérios definidores do modo de funcionamento da $\mathrm{AD}$ para buscar problemas práticos do cotidiano, relacionados à língua e à comunicação, amplia as questões do ensino de língua inglesa: listening, reading, writing e speaking - como foi visto na execução da proposta.

A imersão nas questões do Haiti, no amálgama que o aluno pode fazer com a vida brasileira, pode incentivar novas aquisições na língua estudada, porque o clipe apresentado inclui fatores culturais essenciais para a vida humana: corpo, etnia, nacionalidade, gênero, classe social, entre outros tópicos - fatores que poderão levar o aluno à identificação.

O suporte da Análise do Discurso potencializou os alunos para que melhor se situassem diante do confronto da linguagem com suas leituras de mundo, com outros sujeitos, com diferentes sentidos e com a história.

A imersão cultural, pois, proposta com a tecnologia - clipe - na educação é mais um momento de vivificação da escola frente a uma ação que os estudantes já vivenciam em seu cotidiano, com atualização das músicas de sua preferência.

Portanto, a avaliação de aprendizagem no contexto de um clipe é compreendida numa perspectiva onde o aluno não somente reage quando provocado, mas desenvolva a capacidade de (re) criar, associada a um conjunto de habilidades desenvolvidas para a utilização da língua como instrumento de acesso as mais variadas práticas sociais o que para Freire (2011) é um direito que não pode ser negado ao aprendiz.

A negação do aprendizado não prejudica somente o estudante, mas também o profissional da educação. $\mathrm{O}$ fato de o professor também pertencer a uma classe excluída historicamente interfere de maneira direta no seu rendimento profissional, se este não se libertar dessa lógica.

Isso demonstra como os professores de linguagem têm a responsabilidade de provocar nos alunos a criação de suas possibilidades, objetivando tornarem-se sujeitos críticos nessa nova configuração de estrutura social engenhada mundialmente, através das pressões sociais até então problematizadas vagamente. Na direção de agir, do pensar global, os estudantes hão de desenvolver capacidades de assimilar diversas formas de compreender a Língua Inglesa.

\section{Referências}

BRAGA, J.C.F. Integrando tecnologias no ensino de inglês nos anos finais do ensino fundamental. São Paulo: Somos Mestres, 2012.

BRONCKART, J.P. Atividade de Linguagem, textos e discursos: por um interacionismo sócio-discursivo. São Paulo: EDUC, 2005.

FREIRE, P. Pedagogia da Autonomia: saberes necessários à prática educativa. São Paulo: Paz e Terra, 2011.

GEERTZ, C. The interpetation of the Cultures. United States of America: Basic Books, 1973.

HALL, S. A identidade cultural da Pós-Modernidade. Belo Horizonte: DP\&A, 2006.

$\mathrm{KOCH}$, I G.V. Introdução à linguística textual: trajetória e grandes temas. São Paulo: Martins Fontes, 2006.

MOITA LOPES, L.P. Por uma linguística aplicada indisciplinar. São Paulo: Parábola, 2006.

ORLANDI, E. P. Análise de Discurso: princípios e procedimentos. Campinas: Pontes, 2007.

ORLANDI, E. P. Discurso em análise: sujeito, sentido e ideologia. Campinas: Pontes, 2012.

ORMOND, R.C.S. Uma proposta de multiletramentos através do curta-metragem A Ilha. In: GAMA, A.P.F. et al. Tecnologias, culturas e linguagens no universo das artes. São Paulo: Pedro \& João Editores, 2016. p.35-46.

PÊCHEUX, M. Delimitações, inversões, deslocamentos. Cad. Estud. Ling., n. 19, 1990.

SANTOS, JA. Ensino de língua inglesa: webquest, uma possibilidade de aprendizagem efetiva. 2018. 72f. Dissertação (Mestrado em Ensino) Universidade de Cuiabá, Cuiabá, 2018.

TARDIF, M. Saberes docentes e formação profissional. Petrópolis: Vozes, 2014. 